\title{
Are They Guilty Because of Their Gender?
}

\author{
Ronny Shtarkshall ${ }^{1,}$, Osmo Kontula ${ }^{2}$, Ilsa S. Lottes ${ }^{3}$, Toivo Aavik $^{4}$ and Mario Baras ${ }^{1}$ \\ ${ }^{1}$ The Braun School of Public Health and Community Medicine of the Hebrew University and Hadassah \\ Medical Organization, Jerusalem, Israel \\ ${ }^{2}$ Population Research Institute, Family Federation of Finland, Helsinki, Finland \\ ${ }^{3}$ Dept. of Sociology, University of Maryland, Baltimore, MD, USA \\ ${ }^{4}$ Dept. of Psychology, University of Tartu, Tartu, Estonia
}

\begin{abstract}
This paper explores whether sexual acts of varying degrees of misconduct/violence are judged differently depending on the gender of the actor and the subject. It presents pooled data from four countries regarding the actors and subjects involved in a range of sexual activities. In addition, the paper investigates whether the gender of the observer (study participant) influenced the assessment. Our sample consisted of 3416 students from the United States, Israel, Finland, and Estonia. The research instrument contained 8 sexual scenarios where the gender labels of the actors and subjects were manipulated. In several highly revealing cases, it was found that female actors were assessed more benignly compared to male ones. Men were never assessed more benignly. Our research finding is in line with public records showing that women are less frequently perceived and reported as sexual perpetrators. As a consequence, men may find it more difficult to complain of sexual misconduct against them, and sexual misconduct by women against men may have remained uncounted and disregarded in many cases.
\end{abstract}

Keywords: Sexual misconduct, sexual perpetrators, sexual scenarios, perceptions of sexual misconduct, A study of university students.

One of the authors, encountered several men who had suffered sexual harassment or violence perpetrated by women and had found it extremely difficult to seek help. Some of the men and women in whom they had reluctantly confided had even gone so far as to view the events as an "initiation" or "helping" a shy or inexperienced man. If true, this perception of sexual misconduct by women could impose grave difficulties on men wishing to seek help, in addition to those we perceive women survivors as having, and leave female perpetrators free to continue their abuse. This raises the question of whether sexual misconduct is viewed differently when it is perpetrated by men versus women. The co-authors were interested in the same issue, and in the possibility that there are cultural variations in how sexual misconduct is perceived.

Sexual misconduct in all of its forms has been generally seen as carried out by men (Russell \& Bolen, 2000). Some discussions of sexual misconduct have surmised that this type of inappropriate behaviour is an integral part of patriarchy (Gil \& Anderson, 1999; Russell \& Bolen, 2000; Walby, 1989), phallocentric (Doherty \& Anderson, 2004; Russell \& Bolen, 2000;), and male-dominance oriented (Gruber \& Morgan, 2005; Jewkes \& Abrahams, 2002). White and Kowalski

*Address correspondence to this author at The Braun School of Public Health and Community Medicine of the Hebrew University and Hadassah. P.O.B. 12272, Jerusalem 91120, Israel; Tel: +972-2-6777108;

E-mail: ronnys@ekmd.huji.ac.il identify the perception that men are more aggressive than women as one of the most pervasive and undisputed gender stereotypes, and they examine female aggression from the point of view of feminist theory. Sommers also challenges the traditional feminist perspectives on male violence against women from a traditional female point of view (Sommers, 2004; White \& Kowalski, 1994).

Hannon et al. examined the effects of the gender of the aggressor and the victim (male-female, femalemale, female-female, and male-male) on judgments of sexual aggression on a date. The results showed that ratings of disapproval for the female aggressor-male victim scenario were significantly lower than for the other three gender pairings (Hannon, et al. 2000). We used a similar model of comparison, but whereas their analysis included only one situation, we widened the range to include a whole spectrum of situations of varying degrees of violence or misconduct, thus enabling us to gain a wider and more general perspective.

In addition, the situation described above was labeled as acquaintance rape by about half of the respondents in all gender pairings except in the female aggressor-male victim, which fewer than one fifth rated as acquaintance rape. In another study by Hannon et al., where the characters in the vignettes were assigned gender-neutral names, $96 \%$ of respondents assumed the aggressor was male; $88 \%$ assumed the 
victim was female (Hannon, Kuntz, Van Laar, \& Williams, 1996).

Oswald and Russell investigated perceptions of sexual coercion in heterosexual dating relationships and found that the use of the same coercive techniques (verbal, alcohol, physical force) was rated as more aggressive for men than women (Oswarld \& Russell, 2006). Women's coercive techniques were more likely to be considered promiscuous, and were viewed as aggressive only when the coercion involved a verbal strategy. Oswald and Russell expressed concern that overall, the ratings for perceptions of both aggressiveness and victimization were not very high within their college student sample (ibid.).

Very few studies have examined the effect of the gender of the harasser. Gutek, Morash, and Cohen found that incidents in a workplace environment that were initiated by a female harasser were viewed as less harassing than incidents initiated by a male harasser (Gutek, Morash, \& Cohen, 1983). Using a within-subjects design, Marks and Nelson found that incidents of blatant harassment as well as more subtle forms of harassment were rated similarly for both male and female professors who harassed (Marks \& Nelson, 1993 ).

The researchers in the Katz et al. study concluded that men and women apply different standards to define sexual harassment. Women appear to be more consistent or egalitarian in their ratings, whereas men's interpretation of harassment depends on the gender of the perpetrator (Katz, Hannon, and Whitten, 1996). Reasons cited for the less harsh ratings by men included that the potential harm resulting from sexual harassment was thought to be less severe for men than women, or that men might be flattered by female sexual advances.

After reviewing harassment studies, Osman found that women tended to label potentially sexually harassing dyadic interactions as more serious sexual harassment than men (Osman, 2007). However, as the type of harassment becomes more blatant, the gender differences in harassment ratings disappeared.

The present study does not examine the experiences of sexual misconduct but rather its perceptions by others not involved in the acts.

This article explores the perceptions of heterosexual misconduct perpetrated by both men and women. It examines perceptions of eight types of interactions that include a range of behaviours that could be interpreted as either sexual harassment, sexual coercion, sexual violence, or child sexual abuse, as well as other potentially sexual scenarios that contained mild or no misconduct. We are not aware of a previous study that has done the same. In each vignette, the potential perpetrator (actor) as well as the potential victim (subject) assumes both of the two gender possibilities (male-female, female-male). We consider these heterosexual interactions and examine the influence of the gender of the actor-subject and the gender of the observer on perceptions of sexual misconduct.

We are aware of possible cultural differences between the four countries we conducted our experiment in, but our aim in this paper is to examine the pooled results across the cultures studied in an attempt to establish whether there is a general trend. In order to do this, we designed a special analytical variable. The examination of the differences between the different cultures will be done in a subsequent paper.

We hypothesized that:

$>\quad$ In general, a male actor's conduct will be rated more severely than a female actor's for the same activity.

$>\quad$ Both men and women will rate a male actor's conduct as more serious, but women will be more egalitarian than men.

$>\quad$ The difference in perceived severity will be greatest in cases where misconduct is ambiguous and open to different interpretations, or when it does not involve direct force.

No overall gender difference was hypothesized, because this varied depending on the type of misconduct.

The importance of this article is in that it presents in a single study the perception of seriousness of a whole range of behaviours, gender differences of the actorsubject pairs within the scope of heterosexual behaviour, and differences in the gender of the observer across the effects of different cultures.

\section{METHODS}

\section{Population}

Our study population consisted of a convenience sample of university students from four countries. All of 
the participants were volunteers, who received no remuneration or credit for their participation in the study. The total $\mathrm{N}$ of returned questions was 3451 . We discarded 35 of the returned, filled questionnaires because they did not specify the gender of the participant. The number of participants in each country was 441, 1423, 964, and 623, from Israel, USA, Finland, and Estonia respectively $(\mathrm{N}=3416$; see Table 1). In all four countries the majority of the respondents were women. This was more apparent in the United States, where women constituted $63 \%$ of the respondents, as compared to $57-59 \%$ of the sample in the other three countries.

The number of returned questionnaires was high (over $85 \%$ ) in all four countries, mainly because the questionnaires were administered during class. The proportion of usable questionnaires among those returned was $3416 / 4235$, or $81 \%$. There were no significant differences between the proportion of men and women in the overall population of respondents and those whose questionnaires were usable. The proportion of usable questionnaires from Estonia was slightly lower relative to their proportion in the population. As the students were recruited from different classes, we are unable to compare the demographics of the respondents to the population from which they were drawn.

\section{Ethics Considerations and Permissions}

As students are considered to be under the authority of university instructors, several formal procedures had to be followed in order to receive permission to carry out this research. The study in Israel, the first to be carried out, received formal permission from the Dean of the Faculty of Medicine. The questionnaire was administered during a recess between classes, and the researchers had to announce in writing at the beginning of the questionnaire and orally prior to its administration that no record would be kept of those participating or not participating in the study.

Students at two universities in the United States, one in the south and one in the mid-Atlantic area, as

Table 1: Description of the Study Population

\begin{tabular}{|c|c|c|c|}
\hline & Men & Women & Total \\
\hline Gender of respondents & 1390 (40.7\%) & $2026(59.3 \%)$ & 3416 \\
\hline \multicolumn{4}{|c|}{ Country (\% gender within country category) } \\
\hline Estonia & $257(41.5)$ & $362(58.5)$ & 619 \\
\hline Finland & $423(44.3)$ & $532(55.7)$ & 955 \\
\hline Israel & $191(43.3)$ & $250(56.7)$ & 441 \\
\hline USA & $519(37.0)$ & $882(63.0)$ & 1441 \\
\hline Total & $1390(40.7)$ & $2026(59.3)$ & 3416 \\
\hline \multicolumn{4}{|c|}{ Questionnaire type [see appendix 2] (\% gender within questionnaire type) } \\
\hline Questionnaire a & $375(42.0)$ & $517(58.0)$ & $882(26.1)$ \\
\hline Questionnaire b & $333(39.5)$ & $510(60.5)$ & $843(24.7)$ \\
\hline Questionnaire c & $334(39.5)$ & $511(60.5)$ & $845(24.7)$ \\
\hline Questionnaire d & $348(41.6)$ & $488(58.4)$ & $836(24.5)$ \\
\hline Total & $1390(40.7)$ & $2026(59.3)$ & 3416 \\
\hline \multicolumn{4}{|c|}{ Age (\% within gender category) } \\
\hline $19-24$ & $888(73.5)$ & $1332(74.6)$ & $2220(74.1)$ \\
\hline $25+$ & $320(26.5)$ & $454(25.4)$ & $774(25.9)$ \\
\hline \multicolumn{4}{|c|}{ Relationship status (\% within gender) } \\
\hline Ever married or cohabiting & $293(21.70)$ & $546(27.67)$ & $839(25.25)$ \\
\hline Non-cohabiting & $451(33.41)$ & $727(36.85)$ & $1178(35.45)$ \\
\hline Not in relationship & $606(44.89)$ & $700(35.48)$ & $1306(39.30)$ \\
\hline Total & 1350 & 1973 & $3323(100.0)$ \\
\hline
\end{tabular}


well as one in Finland, completed the questionnaire during regularly scheduled classes. IRBs at both universities approved the study. The participants were informed that the study investigated perceptions of behaviours that might be labeled as sexual misconduct. Both in Finland and Estonia, permission was obtained from faculty. In each country it was emphasized to participants that they had no obligation to participate in the study and that no records would be kept of those who chose to abstain.

\section{Research Instrument}

Our research instrument was a quantitative survey questionnaire with added qualitative comments.

The research instrument was based on the presentation of several vignettes containing sexual scenarios and a request to evaluate the level of misconduct in each scenario on a Likert-like scale of 8 points. The scale ranged from 1 to $2-$ no or negligible misconduct - to 7 to 8 - very grave misconduct. Two other verbal prompters were used on the scale presented to the respondents: low misconduct (3-4) and misconduct (5-6). We deliberately used a wide range of sexual behaviours that respondents could consider from very low to very grave misconduct (see Appendix 1).

Each respondent was presented with 12 vignettes that $s /$ he had to evaluate for level of misconduct. The manipulated variable was the gender label of the actor and the gender label of the subject in eight of the twelve vignettes (3-10). Four of the 12 vignettes were invariant in all four versions of the questionnaire. They were dropped out of these analyses. The rest were so varied as to present three levels of misconduct and all four combinations of actor-subject in equal numbers to all respondents. The combinations presented in this article are the heterosexual combinations. Their variations in the four versions of the questionnaire are given in Appendix 2.

This method was used previously in a similar manner to assess the effect of the gender label on the evaluation of aggressive behaviour in children (Condry \& Ross, 1985; Finkelhor \& Redfield, 1984). Their results showed differences between scores of abuse according to the gender of the perpetrator and the victim (see specifically Table 8-9 on p. 132) (Finkelhor \& Redfield, 1984). But since they were mainly interested in how the public defined sexual abuse, they did not discuss possible biases in the perception of abuse according to gender labels. They were also interested solely in child abuse, while we were interested in a wider range of sexual misconduct (see Appendix 1).

The scenarios were first developed for Israel. At first, 24 scenarios were collected qualitatively from several hundred people who participated in intervention workshops. Then, more than 240 people were asked to rate each scenario for importance, and those that received the greatest number of points were selected. Therefore, they represent the situation concerning sexual misconduct in Israel. For the sake of comparison, they were unvaried between the countries, but apart from minor variations, the situation seemed similar in all Western countries. Scenario 3 (adult and underage girl) is statutory rape in Israel as well as in the U.S. and Finland. Two other scenarios would have been considered grave misconduct comparable to rape (Scenarios 5 and 9). Scenario 4 (professor and student) would be considered misconduct, for which a professor would be fired from the university.

Scenarios 8 and 10 would also be considered misconduct, although to a lesser degree than Scenario 4 because it does not involve sexual contact. Scenario 6 (married person with an unmarried one) has no criminal implications in Israel or in any of the studied countries, although it is considered a capital offense in some Islamic countries. But many people would consider it moral misconduct, so it was considered at the lower end of the scale. The same is true of Scenario 7 (bathing a child and soaping his/her genitals).

We calculated Cronbach alpha for the raw scores and for the z-score for all four versions of the questionnaire in each country (16 variations). For 15 out of the 16 variations, the alpha was $0.70-0.79$. Only one of the Estonian sample variations had a slightly lower value of alpha $=0.68$. Content validity was achieved through extensive expert consultation in Israel, the United States, Finland, and Estonia.

\section{Analysis}

The objects of the study consisted of sub-groups that could potentially differ quite a lot in their estimation of sexual misconduct. For example, it was possible that one gender or an entire country sub-group would systematically evaluate sexual acts as containing a higher level of misconduct compared to the other gender or another country sub-group. Indeed, one of our hypotheses was based on this possibility. 
In order to establish the hypothesized general tendency - that male actors are judged differently compared to female actors in a heterosexual pair, regardless of the participants' culture - we had to use an aggregate of all of our subjects with the different actor-subject pairs. In order to be able to do so and minimize the effects of cultural differences we designed a derived variable "personal z-score". This was the variation of the estimate for a specific vignette from the mean estimate value for all eight vignettes for that specific respondent. This score was used to compare the actor-subject pairs for the aggregate of all respondents and also the ranking of the different pairs.

When we calculated the alphas for the personal zscore we received similar values to the raw scores. This is not surprising, as in transforming from the raw scores to personal z-scores we eliminated some systematic variations. We emphasize that the use of the personal z-score was limited only to the study of the whole aggregate sample, in order to test the most generalized hypothesis.

When we compared the responses by gender subgroups, we used the distribution of the raw scores. For this analysis we recoded the raw scores into a new dichotomous variable. Scores $7-8$ on the Likert-like scale that were verbally labeled in the questionnaire as "very grave misconduct" were labeled as such in the recoded variable, and scores 1-6 were labeled as other. We used this dichotomy because, as noted, an act of misconduct that is perceived as very high is more likely to be reported and investigated. Analysis was carried out using SPSS packages.

\section{RESULTS}

We posed the following question: In cases of a wide range of sexual misconduct scenarios, are perpetrators of the misconduct judged by their gender as much as by their deeds? We present a comparison of the gender labeling of the actor and the subject in heterosexual pairs for a wide range of sexual conduct and misconduct, for male and female respondents.

\section{Score and Ranking of Sexual Misconduct According to the Gender Label of the Actor in a Sexual Scenario}

The aggregate results of our study are reported by the mean "personal z-score" for each vignette by the gender of the perpetrator. As this article presents the results for heterosexual acts, the gender labeling of the subject is also determined by the gender label of the perpetrator. As explained in the methods section, we used the "personal z-score" in order to minimize possible systematic differences in the sub-group of respondents to enable the use of the aggregate results of all of the participants in an attempt to establish whether there is an actor dependent general trend in perceiving the seriousness of sexual misconduct/violence.

These results are reported in Table 2 for the two different heterosexual pairs. It is immediately evident that in seven out of the eight vignettes the estimation of the seriousness of men acting out the sexual scenario is perceived as significantly more serious than women acting out the same scenario. A higher absolute magnitude in negative numbers marks less serious misconduct. We also ranked the misconduct vignettes, of both male and female actors, according to their level of seriousness as determined by our respondents (Table 3). The highest ranked among the various heterosexual vignettes is the one with no difference between male or female actors (Vignette 9). In comparing the personal z-scores we see that the smallest difference between the perception of men and women after Vignette 9 is Vignette 3 , which is legally considered rape. In all other vignettes there is at least a two-rank difference between a male actor and a female one, with the male actor always having a higher rank. In most cases there is a difference of at least three ranks between male and female actors for the same description of an act.

\section{Evaluating a Sexual Act as a Very Grave Misconduct in Variable Vignettes (Vignettes 3-10)}

We also studied the number and proportion of those who considered a sexual act in a vignette to represent very grave misconduct ( 7 and 8 on the Likert-like scale). The reasoning for this is that acts that are socially perceived as very grave misconduct are more likely to be reported and investigated than those considered low misconduct (Holgersson \& Gottschalk, 2008). Although not dealing with sexual misconduct, these references relate to the adjacent field of family violence.

The data in Table 4 show that one vignette (7) has an odds ratio (OR) of almost 10 to be considered very serious misconduct when the actor is a man as compared to a woman; two vignettes (5 and 10 ) have an OR of 2.4, and two more (Vignettes 3 and 4) have a statistically significant $O R$ of more than 1.2 to 1.5 . Three vignettes show no significant difference between 
Table 2: Comparison of mean "Personal z-Scores" for Male-Female and Female-Male Pairs of Labeling of ActorSubject of a Sexual Scenario

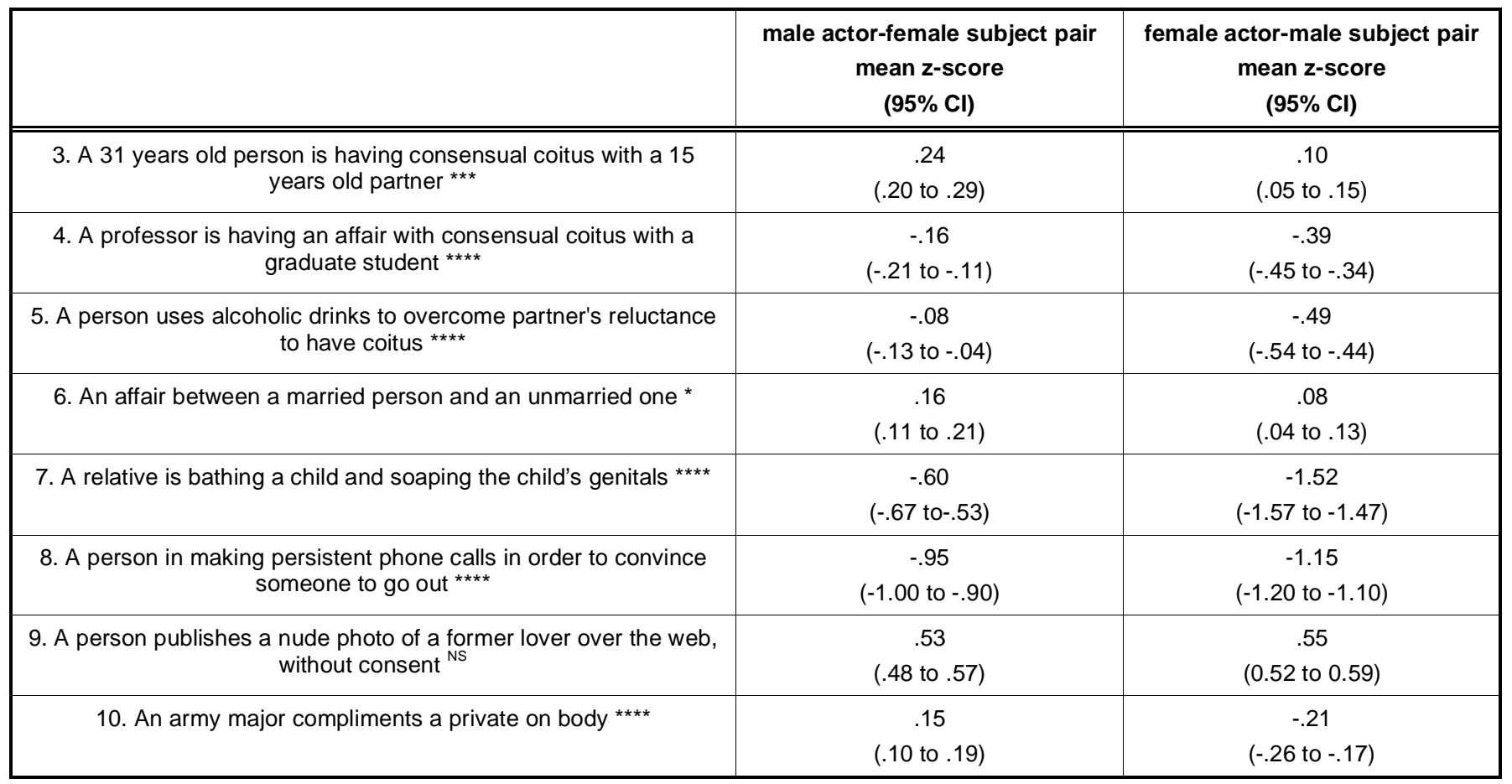

${ }^{\text {NS }}-$ not significant; ${ }^{*}-p \leq .05 ;{ }^{* *}-p \leq .001 ;{ }^{* * *}-p \leq .0001 ;{ }^{* * * *}-p \leq .00001$.

Table 3: Ranking of the Results in Table 2 (in Brackets the Gender of the Actor) [in Square Brackets the Rank of the Complimentary Gender Pair]

\begin{tabular}{|c|c|c|c|c|c|}
\hline Rank & vignette (actor) & z-score & Rank & vignette (actor) & z-score \\
\hline $1-2$ & $\begin{array}{l}\text { Publishing photos over the internet } \\
\qquad(\mathrm{m}, \mathrm{f})\end{array}$ & .54 & 10 & $\begin{array}{l}\text { An army major compliment a private on body (f) } \\
{[6]}\end{array}$ & -.21 \\
\hline $3-4$ & $\begin{array}{l}\text { A } 31 \text { years old man is having sex with a } \\
15 \text { years girl }(\mathrm{m})[7]\end{array}$ & .16 & 11 & $\begin{array}{l}\text { A professor is having an affair with consensual } \\
\text { coitus with a graduate student (f) [10] }\end{array}$ & -.39 \\
\hline 5 & $\begin{array}{l}\text { An army male major compliment a } \\
\text { private on her body }(\mathrm{m})[12]\end{array}$ & .15 & 12 & $\begin{array}{l}\text { A person is using an alcoholic drink to } \\
\text { overcome partner's reluctance for coitus (f) [9] }\end{array}$ & -.49 \\
\hline 7 & $\begin{array}{l}\text { An affair between an unmarried person } \\
\text { and a married one (f) [3-4] }\end{array}$ & .08 & 14 & $\begin{array}{c}\text { A woman is making persistent phone calls to a } \\
\text { a man in order to obtain a date (f) }[16]\end{array}$ & -1.15 \\
\hline 8 & $\begin{array}{l}\text { A person is using alcoholic drinks to } \\
\text { overcome partner's reluctance for coitus } \\
(\mathrm{m})[14]\end{array}$ & -.08 & 15 & $\begin{array}{l}\text { A relative is bathing a child and soaping the } \\
\text { child's genitals (f) [15] }\end{array}$ & -1.52 \\
\hline
\end{tabular}

those who considered the act as very grave misconduct when the gender of the actors was either male or female $(6,8$, and 9$)$. None of the vignettes showed a higher proportion of respondents who considered it to be very grave misconduct when the actor was female as compared to male $(O R<1)$. In summary, in this study, acts of sexual misconduct by male actors were considered either more harshly, or in a minority of cases, as equal to sexual acts of misconduct by female actors, but never less harshly. 
Table 4: Perceived Very High Misconduct By the Gender of the Actor in Heterosexual Actor-Subject Pairs

\begin{tabular}{|c|c|c|c|c|c|c|c|}
\hline \multirow[b]{2}{*}{$\begin{array}{l}\text { Level of misconduct } \\
\text { Vignette }\end{array}$} & \multicolumn{3}{|c|}{$\begin{array}{c}\text { male-female pair } \\
n(\%)\end{array}$} & \multicolumn{3}{|c|}{$\begin{array}{l}\text { female-male pair } \\
\mathrm{n}(\%)\end{array}$} & \multirow[t]{2}{*}{$\begin{array}{c}\text { OR } \\
(95 \% \mathrm{Cl})\end{array}$} \\
\hline & $\begin{array}{l}\text { Other } \\
(1-6)\end{array}$ & $\begin{array}{l}\text { Very high } \\
(7-8)\end{array}$ & Total & $\begin{array}{l}\text { Other } \\
(1-6)\end{array}$ & $\begin{array}{l}\text { Very high } \\
(7-8)\end{array}$ & Total & \\
\hline $\begin{array}{l}\text { 3. A } 31 \text { years old person having sex } \\
\text { with a } 15 \text { years old person * }\end{array}$ & $\begin{array}{c}487 \\
(54.2)\end{array}$ & $\begin{array}{c}411 \\
(45.8)\end{array}$ & 898 & $\begin{array}{c}505 \\
(59.6)\end{array}$ & $\begin{array}{c}343 \\
(40.4)\end{array}$ & 848 & $\begin{array}{c}1.24 \\
(1.03-1.50)\end{array}$ \\
\hline $\begin{array}{l}\text { 4. A professor having an affair with a } \\
\text { graduate student ** }\end{array}$ & $\begin{array}{c}625 \\
(73.8)\end{array}$ & $\begin{array}{c}222 \\
(26.2)\end{array}$ & 847 & $\begin{array}{c}720 \\
(79.8)\end{array}$ & $\begin{array}{c}182 \\
(20.2)\end{array}$ & 902 & $\begin{array}{c}1.41 \\
(1.12-1.76)\end{array}$ \\
\hline $\begin{array}{l}\text { 5. Use of alcoholic drinks to overcome } \\
\text { reluctance to have coitus } \\
* * * *\end{array}$ & $\begin{array}{c}583 \\
(68.7)\end{array}$ & $\begin{array}{c}266 \\
(31.3)\end{array}$ & 846 & $\begin{array}{c}729 \\
(86.2)\end{array}$ & $\begin{array}{c}117 \\
(13.8)\end{array}$ & 849 & $\begin{array}{c}2.42 \\
(1.89-3.10)\end{array}$ \\
\hline $\begin{array}{l}\text { 6. An affair between a married person } \\
\text { and an unmarried one }{ }_{\mathrm{NS}}\end{array}$ & $\begin{array}{c}499 \\
(58.8)\end{array}$ & $\begin{array}{c}349 \\
(41.2)\end{array}$ & 848 & $\begin{array}{c}530 \\
(62.5)\end{array}$ & $\begin{array}{c}318 \\
(37.5)\end{array}$ & 848 & - - - \\
\hline $\begin{array}{l}\text { 7. A relative is bathing a child soaping } \\
\text { the child's genitals ****}\end{array}$ & $\begin{array}{c}663 \\
(74.9)\end{array}$ & $\begin{array}{c}222 \\
(25.1)\end{array}$ & 885 & $\begin{array}{c}818 \\
(96.7)\end{array}$ & $\begin{array}{c}28 \\
(3.3)\end{array}$ & 846 & $\begin{array}{c}9.79 \\
(6.5-14.7)\end{array}$ \\
\hline $\begin{array}{l}\text { 8. Persistent phone calling to convince } \\
\text { to go out }{ }^{N S}\end{array}$ & $\begin{array}{c}806 \\
(95.6)\end{array}$ & $\begin{array}{c}37 \\
(4.4)\end{array}$ & 843 & $\begin{array}{c}867 \\
(96.7)\end{array}$ & $\begin{array}{c}30 \\
(3.3)\end{array}$ & 897 & - - - \\
\hline $\begin{array}{l}\text { 9. Publishing a nude photo of a former } \\
\text { lover over the internet }\end{array}$ & $\begin{array}{c}325 \\
(38.3)\end{array}$ & $\begin{array}{c}524 \\
(61.7)\end{array}$ & 849 & $\begin{array}{c}341 \\
(40.4)\end{array}$ & $\begin{array}{c}503 \\
(59.6)\end{array}$ & 844 & $-\cdots$ \\
\hline $\begin{array}{l}\text { 10. An army major complimenting a } \\
\text { private on body }{ }^{\star \star \star \star}\end{array}$ & $\begin{array}{c}510 \\
(60.0)\end{array}$ & $\begin{array}{c}340 \\
(40.0)\end{array}$ & 850 & $\begin{array}{c}666 \\
(78.4)\end{array}$ & $\begin{array}{c}183 \\
(21.6)\end{array}$ & 849 & $\begin{array}{c}2.43 \\
(1.96-3.0)\end{array}$ \\
\hline
\end{tabular}

NS - not significant; ${ }^{*}-p \leq .05 ;{ }^{* *}-p \leq .01 ;{ }^{* * *}-p \leq .001 ;{ }^{* \star * *}-p \leq .0001$.

Odds Ratio $(\mathrm{OR})$ is calculated for male's actor being perceived as very high misconduct in comparison to female's actor behaviour so perceived in the same act. OR is calculated only for pairs with significant difference in Fisher's exact test.

Comparing the Evaluation of an Act According to the Gender of the Actor and the Gender of the Respondent

When we added the gender of the respondent to the analysis, several additional features of the data emerged. The results of this comparison are presented in Table 5. There are 18 pairs comparing the same actor-subject pair with different genders of respondents. A comparison of the mean raw scores reveals no consistent differences between male and female respondents, but the perception that men's acts are generally judged more harshly persist in part, for both male and female respondents.

Only in three cases (Vignettes 3, 5, and 9) did men judge female actors more leniently than male actors, while women judged them similarly. In the rest of the vignettes both men and women judged male actors more harshly than female ones; however, men were never judged more leniently than women or women more harshly than men, even by female respondents.

\section{DISCUSSION}

This study contained eight vignettes of possible sexual misconduct/violence in which the gender label of the actor could be varied and compared. The important value to observe is the odds ratio (OR) for judging an act as very serious when a man was labeled as the actor, as compared to judging it so when a woman was the labeled actor. Our results support the hypothesis that men are at an excessive risk for being labeled as perpetrators of sexual misconduct/violence because of the difference in the perception of the same acts when perpetrated by a man or a woman (Table 4 ).

There was an interesting exception to men being judged more harshly. Of the various acts, the one labeled as most serious - publishing nude photos of a former lover over the Internet without consent - was viewed as very serious regardless of whether the perpetrator was male or female.

This seems to indicate that when an act is viewed as blatant sexual misconduct, it is not tolerated regardless of the actor's gender. This was supported also in Vignette 3, concerning an adult person having consensual coitus with a 15 -year-old. This supports our third hypothesis that in the cases of higher severity the difference in perception depending on the gender of the actor will be smaller.

One reason for men perceiving female actors more benignly and male actors more harshly than women 
Table 5: Mean Raw Scores of Severity of Misconduct by the Gender Labelling of the Actor and Subject and by the Gender of the Respondents

\begin{tabular}{|c|c|c|c|c|}
\hline \multirow[t]{2}{*}{ Gender Labels of actors \& subjects } & & Male actor-female subject & Female actor-male subject & Sig. difference \\
\hline & \multicolumn{4}{|c|}{ Gender of Respondent } \\
\hline \multirow{3}{*}{ 3. Coitus with 16 years gender disparity } & men & 5.91 & 5.04 & $* * * *$ \\
\hline & women & 5.86 & 5.94 & NS \\
\hline & Sig. diff. & NS & $* * *$ & \\
\hline \multirow{3}{*}{$\begin{array}{l}\text { 4. Professor having an affair with graduate } \\
\text { student }\end{array}$} & men & 5.40 & 4.12 & $* * *$ \\
\hline & women & 5.33 & 4.63 & $* * *$ \\
\hline & Sig. diff. & NS & ** & ----- \\
\hline \multirow{3}{*}{$\begin{array}{l}\text { 5. Use of alcoholic drinks to lower reluctance } \\
\text { to coitus }\end{array}$} & men & 5.23 & 4.48 & $* * *$ \\
\hline & women & 5.25 & 5.35 & NS \\
\hline & Sig. diff. & NS & $* * *$ & ---- \\
\hline \multirow{3}{*}{$\begin{array}{l}\text { 6. An affair between a married person and an } \\
\text { unmarried one }\end{array}$} & men & 5.67 & 5.11 & $* * *$ \\
\hline & women & 5.76 & 5.38 & $* *$ \\
\hline & Sig. diff. & NS & NS & ----- \\
\hline \multirow{3}{*}{$\begin{array}{c}7, \text { A relative bathing a four year old child and } \\
\text { soaping its genitals }\end{array}$} & men & 4.31 & 1.96 & $* * * *$ \\
\hline & women & 3,75 & 1.88 & $* * * *$ \\
\hline & Sig. diff. & $* *$ & NS & ------ \\
\hline \multirow{3}{*}{$\begin{array}{l}\text { 8. Persistent phone calls to obtain a date } \\
\text { ("phone stalking") }\end{array}$} & men & 4.03 & 2.91 & $* * \star *$ \\
\hline & women & 3.07 & 2.82 & * \\
\hline & Sig. diff. & $* * * *$ & NS & ----- \\
\hline \multirow{3}{*}{$\begin{array}{l}\text { 9. Publishing nude photos on the internet } \\
\text { without consent }\end{array}$} & men & 6.85 & 6,63 & * \\
\hline & women & 6.63 & 6.53 & NS \\
\hline & Sig. diff. & * & NS & -------- \\
\hline \multirow{3}{*}{$\begin{array}{l}\text { 10. An army major making sexual comments } \\
\text { on a private's body }\end{array}$} & men & 5.44 & 5.01 & $5.21^{* *}$ \\
\hline & women & 5.98 & 5.59 & $5.79^{\star \star *}$ \\
\hline & Sig. diff. & $* * *$ & $* * * *$ & ----- \\
\hline
\end{tabular}

Significant differences were calculated by t-test for equality of means.

$\mathrm{NS}=$ not significant; ${ }^{*}=\mathrm{p} \leq .05 ;{ }^{* *}=\mathrm{p} \leq .01 ;{ }^{* * *}=\mathrm{p} \leq .001 ;{ }^{* * * *}=\mathrm{p} \leq .0001$.

participants could be that men ascribe more to gender stereotyping than women and therefore perceive their own gender as predators, while perceiving the other gender as victims. Another reason could be that women are more aware that sexual motivations are more abundant within their own gender, contrary to social stereotypes.

Both Israeli and American media report, for example, that women in positions of authority, including teachers and psychologists, are treated much more leniently than men in similar positions, if they are accused of comparable sexual acts. In Israel, the situation has become so problematic that the Knesset (Israeli parliament) is considering changing the language of the law in order to avoid this type of bias.
Vignette 7 could serve as an example of the dangers of over-reporting as well as under-reporting sexual misconduct. In this scenario, a relative is bathing a young child and soaping the child's genitals. The vignette could be interpreted as either a caring act, a neutral act, or as a crime within the family against a pre-pubescent child. It is important to emphasize that in the vignette itself there is no hint of sexual motivation, intent, or satisfaction. It was an interesting but also an alarming finding that men were judged ten times more harshly than women in this vignette. Apparently, it is assumed that men are more likely to be sexually motivated than women when touching other persons. Also, women may be perceived as caregivers and therefore the same act, when carried out by women, is not labeled as sexual. 
This finding raises two concerns. First, the same acts may be over-reported as serious sexual misconduct leading to legal/corrective action when perpetrated by men, while being under-reported when perpetrated by women. Thus, women who do have sexual motivations are more likely to be able to continue their abuse unhampered.

In the case of Finland, we compared statistics from Finnish police records on sex with children in 19922007 with two population surveys conducted near the same time period. They demonstrated that there was indeed a gender bias in reporting and investigating female perpetrators (Kontula \& Haavio-Mannila, 1995; Statistics Finland, 2009). It is impossible to know from these results whether the discrepancy stems from the over-reporting of male acts as misconduct or the underreporting of female sexual acts. It is possible that both mechanisms are acting in concert.

There has been theorizing about male college students and their "culture" of combining alcohol with sex (Abbey, 2002). In our study, we made it clear that the use of alcohol was for the purpose of overcoming reluctance to have coitus. When the labeled actor was a man giving the drinks to a woman, he was viewed almost three times more seriously than a woman for the same act. In many legal systems, including Israel and the U.S. (from which most of our participants were drawn), it is considered a crime to ply someone with liquor in order to lower their resistance to have intercourse. In legal language this is called "sex under the influence". These results indicate that men appear to be at a much higher risk of receiving such accusations. In Israel, some women made comments about this vignette to the effect that "this was helping him out" and viewed reluctance to have sex among men as "un-natural" or "problematic".

In most of our vignettes women were perceived as vulnerable and weak and in a victimized position. If men are generally viewed as predators of women, this can lead to fear and confusion on both sides, and could socialize young boys and girls into adversarial views of each other. The view of boys as predators may also harm their development (Sommers, 2000).

In examining the hypothesis that in perceiving male and female actors differently in heterosexual misconduct women are more egalitarian than men, as demonstrated in Table 5. In Vignettes 3 and 9 women judged male and female actors similarly, while men judged female actors more benignly. In all other vignettes both men and women judged male actors more harshly than female actors, but women participants were more egalitarian in all cases.

One troubling possibility stemming from this research is that people's reactions to sexual misconduct/violence and its effects are also shaped by sex role stereotypes and societal expectations. Thus, the varying nature and extent of the responses to sexual misconduct by men and women may be shaped by internalized social views of gender roles and the expectation to have specific reactions. This may lead to social injustice and magnification of social discrepancies between the genders. The perception of women as victims, for example, may foster victimization.

Our study adds to previous studies in examining a whole range of sexual acts in a single study, from no sexual misbehaviour or violence to very grave acts. This enables us to propose that in the case of blatant acts of sexual misconduct there are no differences or little difference with regard to male or female aggressors. When the acts are ambiguous or "soft", men are judged much more harshly. Our study therefore implies some likelihood of over-reporting of men as sexual aggressors and under-reporting of women. Both situations could be very problematic from the point of view of the ability to live in security. We posit that this point to a need to educate/socialize both men and women to view sexual misconduct/violence in a more egalitarian and realistic view.

\section{LIMITATIONS OF THE PRESENT STUDY}

One limitation of this study was that the adopted measurements cover only some sexual scenarios. There may be many other scenarios that could provide important additional information for the purposes of this study. Another important limitation is that the present study was carried out only among university students. Other population groups, such as adults and the less educated, could harbour different perceptions of sexual misconduct and of the role of gender. One could predict that in a society with more progressive gender equality gender-based perceptions of sexual misconduct would decrease. Societies with advanced sexual equality could be expected to practice greater equity in terms of the impact of the gender of a perpetrator of sexual misconduct. This hypothesis should be tested in future studies, calling for further research particularly among representative population samples and the professionals involved in reporting and investigating sexual crimes. 


\section{CONCLUSION}

We have positively demonstrated our three hypotheses. (1) Male actors' misconduct was generally rated more seriously. In few cases there was no significant difference but women actors' misconduct was never rated more seriously in this study. (2) Both men and women were rating male actors' misconduct more seriously as compared to female actors' misconduct. (3) The differences between male and female actors were the greatest in scenarios of small or ambiguous misconduct. They were the smallest in the more blatant/serious scenarios.
We conclude that Boys and men who experience harassment have remained marginal because men are labeled as alleged sexual predators and women as innocent victims in much of the public discourse. The implication of this praxis has been that sexual misconduct against men and boys has often remained uncounted. The shortage of counselling and treatment services to male victims of sexual abuse by women should be confronted through adequate training that includes more realistic knowledge of sexual harassment and misconduct.

\section{APPENDIX 1: The 12 Vignettes as Presented in the Heterosexual Versions of the Questionnaires}

1. A 15-year-old boy persuades his same-age girlfriend to have vaginal sexual intercourse.

2. A man forces another man to have sex with him by using physical force.

3. A 31-year-old man/woman has sex with a sexually experienced 15-year-old girl/boy.

4. A married female/male professor is having a relationship that includes consensual sex with a male/female graduate student in her/his department. The student is not under her/his direct supervision.

5. A man/woman who is courting another woman/man gives her/him alcoholic drinks in order to overcome her/his hesitations about having sex.

6. A married woman/man is having an affair with an unmarried man/woman.

7. An uncle/aunt in his/her 30 s is bathing a 4-year-old girl/boy and washes her/his genitals.

8. A woman/man calls a man/woman every day for several weeks in order to persuade him/her to go out.

9. A man/woman who had a relationship with another woman/man photographed her/him in the nude with her/his consent. After they separated, he/she published the pictures on the Internet without consent.

10. A female/male army major repeatedly makes complimentary remarks about the shape and "manliness"/"womanliness" of a young male/female soldier under her/his command.

11. A 15-year-old girl tells her same-age boyfriend that unless he has intercourse with her she will end their relationship.

12. A young woman, babysitting a 5-year-old girl, plays with the child's genitals for sexual gratification. The girl giggles and does not object.

Vignettes: 1, 2, 11, and 12 were invariant in all versions of the questionnaire.

APPENDIX 2: The Distribution of the Gender of the Actor-Subject Heterosexual Pairs in the Four Versions of the Questionnaire

\begin{tabular}{|c|c|c|c|c|}
\hline $\begin{array}{c}\text { Scenario } \\
\text { [short description) }\end{array}$ & Questionnaire a & Questionnaire b & Questionnaire c & Questionnaire d \\
\hline $\begin{array}{l}\text { 3. A 31-year-old person having sex with a } \\
\text { 15-year-old person }\end{array}$ & $m-f^{*}$ & $f-m$ & - & - \\
\hline $\begin{array}{l}\text { 4. A professor having an affair with a } \\
\text { graduate student }\end{array}$ & $f-m$ & - & - & $m-f$ \\
\hline $\begin{array}{l}\text { 5. Use of alcoholic drinks to overcome } \\
\text { reluctance to have sex }\end{array}$ & - & - & $m-f$ & $f-m$ \\
\hline
\end{tabular}




\begin{tabular}{|c|c|c|c|c|}
\hline $\begin{array}{l}\text { 6. An affair between a married person and } \\
\text { an unmarried one }\end{array}$ & - & $m-f$ & $f-m$ & - \\
\hline $\begin{array}{l}\text { 7. A relative bathing a child and soaping } \\
\text { the child's genitals }\end{array}$ & $m-f$ & $\mathrm{f}-\mathrm{m}$ & - & - \\
\hline $\begin{array}{l}\text { 8. Persistent phone calls to convince } \\
\text { someone to go out }\end{array}$ & $f-m$ & - & - & $m-f$ \\
\hline $\begin{array}{l}\text { 9. Publishing a nude photo of a former } \\
\text { lover over the Internet }\end{array}$ & - & - & $m-f$ & $m-f$ \\
\hline $\begin{array}{l}\text { 10. An army major complimenting a } \\
\text { private's body }\end{array}$ & - & $m-f$ & $f-m$ & - \\
\hline
\end{tabular}

*Gender designation: $m=$ male $; \mathrm{f}=$ female.

Actor-subject axis: Left letter in a pair = active partner - actor. Right letter in pair $=$ passive partner - subject.

\section{REFERENCES}

Abbey Augustus. 2002. Alcohol-Related Sexual Assault: A Common Problem among College Students. Journal of the studies of Alcohol (Supplement 14): 118-128.

Condry John C., and David F. Ross 1985. Sex and Aggression: The Influence of Gender Label on the Preception of Aggression in Children. Child development 56(1): 225-233.

http://dx.doi.org/10.2307/1130189

Doherty, Kathy and Irina Anderson 2004. Making Sense of Male Rape: Constructions of Gender, Sexuality and Experience of Sex Victims. Journal of Community and Applied Social Psychology 14(2): 85-103. http://dx.doi.org/10.1002/casp.765

Finkelhor, David, and Redfield, Dennis 1984. How the Public Defines Sexual Abuse. In Finkelhor D (ed), Child Sexual Abuse: New Theory and Research. New York, NY: The Free Press, 107133.

Gruber, James and Phoebe Morgan (eds.) 2005. In the Company of Men - Male Dominance and Sexual Harassment. Boston, MA: Northeastern University Press.

Gutek Barbara A, Bruce Morash, and Aaron G Cohen, 1983. Interpreting Social-sexual Behavior in a Work Setting. Journal of Vocational Behavior 22:30-48. http://dx.doi.org/10.1016/0001-8791(83)90004-0

Hannon Roseann, David S. Hall, Holly Nash, Jean Formati, and Tina Hopson, 2000. Judgments Regarding Sexual Aggression as a Function of Sex of Aggressor and Victim. Sex Roles 43(5/6): 311-322. http://dx.doi.org/10.1023/A:1026643225329

Hannon Roseann, Todd Kuntz, Sonja Van Laar, and Jennifer Williams 1996. College Student's Judgments Regarding Sexual Aggression During Date. Sex Roles 35(11/12): 765778. Springer.com/article/10.007/BF01544091\#page-2

Holgersson Stefan and Petter Gottschalk (2008) Police officers' Professional Knowledge. Police Practice and Knonwledge (iFirst): 1-13. http://www.tandfonline.com/doi/full/10.1080/ $15614260801980802 \#$ \#review

Jewkes Rachel and Naeema Abrahams 2002. The Epidemiology of Rape and Sexual Coercion in South Africa: An Overview.
Social Science \& Medicine 55(7): 1231-1244. Doi:10.1015/S0277-9536(01)00242-8

Katz Roger C., Roseann Hannon, and Leslie Whitten 1996. Effects of Gender and Situation on the Perception of Sexual Harassmen. Sex Roles 34(1/2): 35-42.

http://dx.doi.org/10.1007/BF01544794

Kontula Osmo, and Elina Haavio-Mannila 1995. Sexual Pleasures: Enhancement of Sex Life in Finland, 1971 - 1992. Hampshire Dartmouth.

Marks Michelle A. and Eileen S. Nelson 1993. Sexual Harassment on Campus: Effects of Professor Gender on Perceptions of Sexually Harassing Behaviors. Sex Roles 28(3/4): 207-217. http://dx.doi.org/10.1007/BF00299281

Osman Suzanne L 2007. Predicting Perceptions of Sexual Harassment Based on Type of Resistance and Belief in Token Resistance. The Journal of Sex Research 44(4): 340346.

http://dx.doi.org/10.1080/00224490701586714

Oswald Debra L., and Brenda L. Russell 2006. Perceptions of Sexual Coercion in Hetersoexual Dating Relationships: the role of Aggressor Gender and Tactics. Jounal of Sex Research 43(1): 87-95.

http://dx.doi.org/10.1080/00224490609552302

Russell, Diana E. H., and Bolen, Rebecca M. 2000. The Epidemic of Rape and Child Sexual Abuse in the United States. Thousand Oaks, CA: Sage Publications.

Sommers C H (2000) The war against boys: how misguided feminism is harming our young men. New York: Simon and Schuster.

Sommers C H (2004) Researching the "rape culture" of America. [Electronic Version]. Retrieved June 2009 from http://www.leaderu.com/real/ri9502/sommers.html.

Statistics Finland (2009) Offenses Known to the Police. http://www.stat.fi/til/polrik/index_en.html.

White J, and Kowalski R (1994) Deconstructing the myth of the nonaggressive woman. Psychology of Women Quarterly 18(4): 487-508. http://dx.doi.org/10.1111/j.1471-6402.1994.tb01045.x

\section{DOI: http://dx.doi.org/10.6000/1929-4409.2015.04.04}

(c) 2015 Shtarkshall et al.; Licensee Lifescience Global.

This is an open access article licensed under the terms of the Creative Commons Attribution Non-Commercial License (http://creativecommons.org/licenses/by-nc/3.0/) which permits unrestricted, non-commercial use, distribution and reproduction in any medium, provided the work is properly cited. 